\title{
DETERMINAN FAKTOR TERHADAP PERILAKU HIDUP BERSIH DAN SEHAT PADA SKALA RUMAH TANGGA DI DESA MENDALOK KECAMATAN SUNGAI KUNYIT KABUPATEN MEMPAWAH
}

\section{DETERMINANT FACTORS ON CLEAN AND HEALTHY LIVING BEHAVIOR AT THE HOUSEHOLD SCALE IN MENDALOK VILLAGE, SUNGAI KUNYIT SUB-DISTRICT, MEMPAWAH REGENCY}

\author{
Muhammad Fachmi ${ }^{1)^{*}}$, Sandri Wiratman ${ }^{2)}$ \\ ${ }^{1,2}$ Fakultas IImu Kesehatan, Universitas Muhammadiyah Pontianak, Jl. A. Yani, Pontianak \\ *e-mail: muhammadfahmi8877@gmail.com
}

Diterima: 16 April 2021, Revisi: 23 Juni 2021, Diterbitkan: 30 Juni 2021

\begin{abstract}
Clean and Healthy Living Behavior (PHBS) is an effort to provide a learning experience or create a condition for individuals, families, groups and communities. The present study was designed to examine the determinants of clean and healthy living behaviour on a household scale in Mendalok Village, Sungai Kunyit District, Mempawah Regency. It was a quantitative approach involving a sample of 175 people selected by proportional random sampling. The data were collected using questionnaires and checklist sheets. They were analysed using Chi-Square statistical test. The research found that the variables related to clean and healthy living behaviour were knowledge ( $p$ value $=0.006)$, attitude $(p$-value $=0.022)$, counseling $(p$-value $=0.001)$ and education $(p$-value $=$ 0.032). To promote PHBS, routine counselling was required at least once a month, providing motivation, concrete examples, and support for the community to change clean and healthy living behaviour such as running environmental hygiene competitions and cooperation activities.
\end{abstract}

Keywords: Knowledge, Attitude, Counselling, Education, Healthy and Clean Life Behavior

\section{ABSTRAK}

Perilaku Hidup Bersih dan Sehat (PHBS) merupakan upaya untuk memberikan pengalaman belajar atau menciptakan kondisi bagi perorangan, keluarga, kelompok dan masyarakat. Tujuan penelitian adalah untuk mengetahui determinan faktor terhadap perilaku hidup bersih dan sehat pada skala rumah tangga di Desa Mendalok, Kecamatan Sungai Kunyit, Kabupaten Mempawah. Pendekatan penelitian ini bersifat kuantitatif dengan melibatkan sampel sebanyak 175 orang yang ditentukan dengan proporsional random sampling. Data dikumpulkan menggunakan kuesioner dan lembar checklist. Analisis data dilakukan dengan uji statistik Chi Square. Hasil penelitian ini menunjukkan bahwa variabel yang berhubungan dengan perilaku hidup bersih dan sehat yaitu, pengetahuan ( $p$ value $=0,006)$, sikap ( $p$ value $=0,022)$, penyuluhan $(p$ value $=0,001)$ dan pendidikan $(p$ value $=$ 0,032 ). Untuk memasyarakatkan PHBS diperlukan penyuluhan rutin minimal 1 bulan sekali, pemberian motivasi, contoh yang nyata, dan dukungan kepada masyarakat untuk mengubah perilaku hidup bersih dan sehat seperti mengadakan lomba kebersihan lingkungan dan kegiatan gotong royong.

Kata Kunci: Pengetahuan, Sikap, Penyuluhan, Pendidikan, Perilaku Hidup Bersih dan Sehat

\section{PENDAHULUAN}

Perilaku hidup bersih dan sehat (PHBS) adalah semua perilaku kesehatan yang dilakukan atas kesadaran sehingga anggota keluarga atau keluarga dapat menolong dirinya sendiri di bidang kesehatan dan berperan aktif dalam kegiatan-kegiatan kesehatan di masyarakat. Dalam misi Indonesia Sehat, terdapat suatu upaya membudayakan perilaku hidup bersih dan sehat serta memotivasi kemandirian masyarakat dalam bidang kesehatan, meningkatkan pelayanan kesehatan kepada 
masyarakat yang bermutu, merata dan terjangkau, serta meningkatkan peran serta dan kemitraan masyarakat dalam pembangunan kesehatan. Menurut WHO, kesehatan adalah keadaan sempurna baik fisik, mental, maupun sosial dan tidak hanya bebas dari penyakit dan cacat. Pada batasan yang terdahulu, kesehatan dapat mencakup tiga aspek yakni fisik, mental dan sosial, tetapi menurut Undang-undang No. 23 Tahun 1992 kesehatan dapat mencakup empat aspek yakni fisik (badan), mental (jiwa), sosial dan ekonomi (Notoatmodjo, 2018).

PHBS merupakan suatu upaya untuk memberikan pengalaman belajar atau menciptakan suatu kondisi bagi perorangan, keluarga, kelompok dan masyarakat, dengan membuka jalur komunikasi, memberikan informasi dan melakukan edukasi, untuk meningkatkan pengetahuan, sikap dan perilaku, melalui pendekatan pimpinan (advocacy), bina suasana (social support), dan memberdayakan masyarakat (empowerment), sebagai suatu upaya untuk membantu masyarakat mengenali dan mengatasi masalah sendiri dan dalam tatanan rumah tangga agar dapat menerapkan cara-cara hidup sehat dalam rangka menjaga, memelihara dan meningkatkan kesehatannya (Kesehatan \& Rl, 2017).

PHBS dapat dilakukan dengan melakukan pembiasaan seperti menjaga kebersihan lingkungan, olahraga teratur, dan mengonsumsi makanan bergizi. Pemberdayaan masyarakat dalam upaya penerapan PHBS sangat penting dilakukan karena kebiasaan ini dimulai dari rumah tangga atau keluarga. Penerapan PHBS sudah seharusnya menjadi kebiasaan sehari-hari.
Meskipun terkesan sederhana, pada kenyataannya masih banyak orang yang kurang memperhatikan pentingnya PHBS bagi kesehatan diri sendiri, keluarga, dan lingkungan. (Jauhari, 2014).

Penerapan dari perilaku di tingkat rumah tangga merupakan bentuk pemberdayaan semua anggota keluarga agar mereka mengetahui, mau, dan dapat menerapkan PHBS pada kehidupan sehari-hari. Anggota keluarga juga diharapkan ikut berperan aktif di dalam gerakan kesehatan pada lingkungan masyarakat. Salah satu upaya yang dilakukan adalah melalui kegiatan promosi kesehatan yang terintegrasi. Upaya tersebut bertujuan agar PHBS dapat tercapai dan nantinya masyarakat akan lebih paham tentang kesehatan yang terjadi pada individu dan di lingkungan masyarakat.

Kementerian Kesehatan pada tahun 2017 menyebutkan bahwa capaiannya masih di bawah indikator pencapaian yang dicanangkan dalam Rencana Strategis pada tahun 20162020. Capaian target rumah yang sudah melakukan perilaku hidup bersih dan sehat di dalam kehidupan sehari-harinya untuk tahun 2020 dan untuk memiliki PHBS yang baik capaian angkanya di atas 70\% (Kementerian Kesehatan RI, 2020).

Program PHBS di semua tingkat telah berjalan sesuai dengan program yang ada. Kabupaten Pontianak adalah kabupaten yang telah melaksanakan program PHBS di semua tingkatan; salah satunya adalah Puskesmas Semudun Kecamatan Sungai Kunyit. Merujuk kepada data Puskesmas Semudun tahun 2020, rumah tangga yang berperilaku hidup bersih dan sehat di Desa Semudun berjumlah 73,33\%, di Desa Mandalok berjumlah 53,33\%, 
di Desa Sungai Dungun berjumlah $60,00 \%$ dan di Desa Semparong Paret Raden berjumlah 56,67\%. Rata-rata persentase tatanan rumah tangga berperilaku hidup bersih dan sehat adalah $60,83 \%$.

\section{METODE}

Penelitian ini merupakan penelitian observasional deskriptif korelatif (Azwar, 2017) yang mencari hubungan variabel-variabel pendidikan, pengetahuan, sikap dengan perilaku hidup bersih dan sehat pada tatanan rumah tangga, dengan pendekatan cross sectional dan komunikasi tidak langsung observasi.

Populasi penelitian adalah masyarakat yang tinggal di 9 RT Desa Mendalok dalam wilayah kerja Puskesmas Semudun, Kecamatan Sungai Kunyit dengan jumlah 310 KK. Merujuk kepada rumus penentuan sampel (Azwar, 2017), maka sampel pada penelitian ini berjumlah 175 orang. Data dikumpulkan dengan teknik wawancara, dan instrumennya adalah kuesioner serta lembar checklist observasi. Proses pengumpulan informasi dilakukan dengan menerapkan protokol kesehatan yaitu, memakai masker, hand sanitizer, dan jaga jarak.

Untuk mendapatkan data yang valid dan reliabel, kuesioner diuji validitasnya dengan menggunakan teknik korelasi product moment. Item soal pada koesioner penelitian dikatakan valid apabila $r$ hitung $>r$ tabel (Arikunto, 2016).

Berdasarkan hasil uji coba kuesioner penelitian, 40 item soal dinyatakan valid. Item soal tersebut terdiri atas 16 soal variabel pengetahuan, 12 soal variabel sikap, 4 soal variabel peyuluhan, dan 8 soal variable PHBS. $\begin{array}{ccr}\text { Data } & \text { dianalisis } & \text { dengan } \\ \text { pendekatan } & \text { kuantitatif } & \text { untuk } \\ \text { mengetahui } & \text { faktor-faktor } & \text { yang }\end{array}$ berhubungan dengan perilaku hidup bersih dan sehat di tatanan rumah tangga di Desa Mendalok wilayah kerja Puskesmas Semudun, Kecamatan Sungai Kunyit, Kabupaten Mempawah. Data yang terkumpul dianalisis dengan teknik analisis univariat dan analisis bivariat. Uji statistik untuk melihat kedua variabel adalah uji Chi square (Sugiyono, 2018). Selanjutnya, proses pengolahan data meliputi editing, coding, scoring, entering, dan tabulating.

\section{HASIL DAN PEMBAHASAN}

\section{Analisa Univariat}

Tabel 1. Distribusi Frekuensi Determinan Faktor terhadap Perilaku Hidup Bersih dan Sehat pada skala rumah tangga di desa mendalok Kecamatan Sungai Kunyit Kabupaten Mempawah

\begin{tabular}{lcc}
\hline \multicolumn{1}{c}{ Variabel } & Frek & $\%$ \\
\hline Pengetahuan & & \\
Kurang $(\leq 13)$ & 101 & 57,7 \\
Baik (>13) & 74 & 42,3 \\
\hline Sikap & & \\
Tidak Mendukung $(\leq 10)$ & 88 & 50,3 \\
Mendukung (>10) & 87 & 49,7 \\
\hline Penyuluhan & & \\
Tidak Pernah ( $\leq 3)$ & 91 & 52,0 \\
Pernah (>3) & 84 & 48,0 \\
\hline Pendidikan & & \\
Dasar (SD) & 38 & 21,7 \\
Menengah (SMP, SMU) & 114 & 65,1 \\
Tinggi (PT) & 23 & 13,1 \\
\hline Jamban Keluarga & & \\
Tidak Ada & 17 & 9,7 \\
Ada & 158 & 90,3 \\
\hline Sumber Air Bersih & & \\
Tidak Ada & 57 & 32,6 \\
Ada & 118 & 67,4 \\
\hline Tempat Sampah & & \\
Tidak Ada & 91 & 52,0 \\
\hline
\end{tabular}




\begin{tabular}{|c|c|c|}
\hline Ada & 84 & 48,0 \\
\hline \multicolumn{3}{|c|}{ Kartu Dana Sehat } \\
\hline Tidak Ada & 91 & 52,0 \\
\hline Ada & 84 & 48,0 \\
\hline \multicolumn{3}{|l|}{ Kotak Obat } \\
\hline Tidak Ada & 134 & 76,6 \\
\hline Ada & 41 & 23,4 \\
\hline \multicolumn{3}{|c|}{$\begin{array}{l}\text { Perilaku Hidup Bersih } \\
\text { dan Sehat }\end{array}$} \\
\hline Kurang $(\leq 6)$ & 116 & 66,3 \\
\hline Baik (>6) & 59 & 33,7 \\
\hline Total & 175 & 100,0 \\
\hline
\end{tabular}

Tabel 1 menunjukkan bahwa dari 175 sampel, responden yang pengetahuannya kurang mencapai 101 orang $(57,7 \%)$, dan yang pengetahuannya baik adalah 74 orang (42,3\%). Selanjutnya, responden yang sikapnya tidak mendukung berjumlah paling banyak yaitu, 88 orang $(50,3 \%)$ sedangkan responden yang sikapnya mendukung sebanyak 87 orang (49,7\%).

Responden yang tidak pernah mengikuti penyuluhan berjumlah paling banyak yaitu, 91 orang $(52,0 \%)$, dan responden yang mengikuti penyuluhan sebanyak 84 orang (48,0\%). Responden yang memiliki pendidikan lebih banyak yaitu menengah sebanyak 114 orang $(65,1 \%)$, dan dasar sebanyak 38 orang (21,7\%). Responden yang memiliki pendidikan berjumlah paling sedikit yaitu, 23 orang (13,1\%).

Responden yang memiliki jamban sebanyak 158 orang $(90,3 \%)$ dan yang tidak memiliki jamban sebanyak 17 orang $(9,7 \%)$. Responden yang memiliki sumber air bersih sebanyak 118 orang $(67,4 \%)$ dan yang tidak memiliki sumber air bersih sebanyak 57 orang (32,6\%). Responden yang memiliki tempat sampah sebanyak 84 orang $(48,0 \%)$ dan yang tidak memiliki tempat sampah sebanyak 91 orang $(52,0 \%)$.
Responden yang memiliki kartu dana sehat sebanyak 84 orang $(48,0 \%)$ dan yang tidak memiliki kartu dan sehat sebanyak 91 orang $(52,0 \%)$. Responden yang memiliki kotak obat sebanyak 41 orang $(23,4 \%)$ dan yang tidak memiliki kotak obat sebanyak 134 orang (76,6\%).

Responden yang berperilaku hidup bersih dan sehatnya kurang paling banyak yaitu 116 orang $(66,3 \%)$ dan yang berperilaku hidup bersih dan sehatnya baik sebanyak 59 orang $(33,7 \%)$.

\section{Analisa Bivariat}

Tabel 2. Determinan Faktor terhadap Perilaku Hidup Bersih dan Sehat pada skala rumah tangga di desa mendalok Kecamatan Sungai Kunyit Kabupaten Mempawah

\begin{tabular}{lccccc}
\hline \multirow{2}{*}{ Variabel } & \multicolumn{4}{c}{ PHBS } & \multirow{2}{*}{$\boldsymbol{p}$} \\
\cline { 2 - 4 } & \multicolumn{2}{c}{ Kurang } & \multicolumn{2}{c}{ Baik } & value \\
\cline { 2 - 4 } & $\mathbf{n}$ & $\%$ & $\mathbf{n}$ & $\%$ & \\
\hline Pengetahuan & & & & & \\
Kurang & 76 & 75,2 & 25 & 24,8 & 0,006 \\
Baik & 40 & 54,1 & 34 & 45,9 & \\
\hline Sikap & & & & & \\
Tidak & & & & & \\
Mendukung & 66 & 75,0 & 22 & 25,0 & 0,022 \\
Mendukung & 50 & 57,5 & 37 & 42,5 & \\
\hline Penyuluhan & & & & & \\
Tidak Pernah & 71 & 78,0 & 20 & 22,0 & 0,001 \\
Pernah & 45 & 53,6 & 39 & 46,4 & \\
\hline Pendidikan & & & & & \\
Dasar (SD) & 22 & 57,9 & 16 & 42,1 & \\
Menengah & 83 & 72,8 & 31 & 27,2 & 0,032 \\
(SMU, SMP) & & & & & \\
Tinggi (PT) & 11 & 47,8 & 12 & 52,2 & \\
\hline
\end{tabular}

Tabel 2 menunjukkan bahwa responden yang pengetahuannya kurang cenderung memiliki perilaku hidup bersih dan sehat yang kurang pula, 76 orang (75,2\%). Jumlah mereka lebih besar daripada responden yang pengetahuannya baik, 40 orang (54,1\%). Hasil uji statistik Chi-Square menunjukkan 
bahwa nilai $p=0,006$ lebih kecil dari $\alpha=0,05$, yang artinya Ho ditolak dan Ha diterima. Hasil ini menunjukkan bahwa terdapat hubungan yang bermakna antara tingkat pengetahuan kepala keluarga dengan perilaku hidup bersih dan sehat (PHBS) pada tatanan rumah tangga di Desa Mendalok Wilayah kerja Puskesmas Semudun, Kecamatan Sungai Kunyit.

Hasil observasi menunjukkan bahwa mayoritas masyarakat Desa Mendalok, wilayah kerja Puskesmas Semudun, Kecamatan Sungai Kunyit, idak mengerti tentang perilaku hidup bersih dan sehat seperti masih banyak yang tidak memiliki tempat sampah dan kartu dana sehat $(52,0 \%)$, dan tidak memiliki kotak obat $(76,6 \%)$. Dengan tidak adanya tempat sampah, kartu dana sehat dan kotak obat, masyarakat perlu aktif melakukan konsultasi ke pemerintah setempat dan mereka perlu mendapatkan dukungan pemerintah dalam meningkatkan PHBS di Desa Mendalok.

Rumah tangga yang tidak memiliki tempat sampah atau sarana sanitasi, kartu dana sehat dan kotak obat menunjukkan kurangnya pengetahuan mereka tentang pentingnya PHBS itu. Pengetahuan yang kurang baik dapat mempengaruhi sikap dan perilaku seseorang dalam melakukan suatu tindakan dan upaya pencegahan terhadap peningkatan perilaku hidup bersih dan sehat itu Jauhari (2014) menyatakan bahwa terdapat hubungan yang bermakna antara pengetahuan dengan perilaku hidup bersih dan sehat di Kecamatan Pontianak Selatan. Rogers (2018) melaporkan bahwa perubahan perilaku terjadi melalui tahapan awarenes (kesadaran), interest, evaluation, trial, dan adoption; dan menyimpulkan bahwa apabila penerimaan perilaku melalui proses pengetahuan yang didasari juga oleh kesadaran, maka perilaku tersebut akan bersifat langgeng (long lasting), sebaliknya apabila perilaku tidak didasari oleh kesadaran pada diri seseorang tersebut maka perilaku itu tidak akan bertahan lama.

Hasil penelitian ini tidak sejalan dengan penelitian yang dilakukan oleh Widyastuti \& Hilal (2018) yang menyatakan tidak adanya hubungan antara tingkat pengetahuan dengan PHBS Rumah Tangga di Desa Banjarsari Kulon Kabupaten Banyumas ( $p$ value $=$ 0,085 ). Berdasarkan hasil penelitian ini pengetahuan yang kurang cenderung memiliki PHBS kurang sebesar $75,2 \%$ dibandingkan dengan masyarakat yang memiliki pengetahuan baik. Mengingat bahwa semakin buruknya pengetahuan masyarakat tentang PHBS, maka semakin kurang pula upaya-upaya yang dilakukan masyarakat untuk menciptakan peluang PHBS tersebut. Oleh karena itu, perlu adanya upayaupaya yang dilakukan untuk meningkatkan pengetahuan masyarakat dalam bentuk misalnya, penyuluhan tentang PHBS mengenai jamban keluarga (JAGA), sarana air bersih (SAB), tempat sampah, sarana pembuangan air limbah, ventilasi rumah, kepadatan rumah, dan lantai rumah.

Responden yang sikapnya tidak mendukung cenderung kurang berperilaku hidup bersih dan sehat, 66 orang $(75,0 \%)$. Jumlah responden kelompok ini lebih besar dibandingkan dengan responden yang bersikap mendukung, 50 orang (57,5\%). Uji statistik Chi-Square menghasilkan nilai $p=0,022$ lebih kecil dari $\alpha=0,05$, yang artinya Ho ditolak (Ha diterima). Jadi dapat 
disimpulkan bahwa terdapat hubungan yang bermakna antara sikap kepala keluarga dengan PHBS pada tatanan rumah tangga di Desa Mendalok, Wilayah kerja Puskesmas Semudun, Kecamatan Sungai Kunyit. Hasil penelitian ini sejalan dengan yang dilakukan oleh Supratman (2015) yang mengatakan bahwa terdapat hubungan yang bermakna antara sikap dengan PHBS dengan jumlah sampel 128 di daerah Lombok Timur Nusa Tenggara Barat ( $p$ value $=0,028)$. Notoatmodjo (2018) merujuk sikap kepada penilaian yang umumnya berupa pendapat seseorang terhadap stimulus atau objek. Terbentuknya suatu sikap banyak dipengaruhi oleh faktor perangsang yang timbul dari lingkungan sosial dan kebudayaan misalnya, keluarga, norma, adapt istiadat dan kepercayaan. Sikap seseorang tidak selalu berbentuk perbuatan. Faktor-faktor yang mempengaruhi sikap berperilaku terdiri dari faktor intern dan faktor ekstern.

Hasil penelitian ini tidak sejalan dengan hasil penelitian yang dilaporkan oleh Fitriyani (2012) yang menyatakan bahwa tidak ada hubungan antara sikap dengan PHBS pada penjamah makanan di lesehan sepanjang Jalan Malioboro Yogyakarta ( $p$ value $=0,234$ ). Dalam hal ini, sikap yang tidak mendukung cenderung beresiko memiliki perilaku hidup kurang bersih dan sehat (PHBS) (75,0\%) dibandingkan dengan masyarakat yang memiliki sikap yang baik. Oleh karena itu, perlu adanya upaya-upaya yang dapat dilakukan untuk meningkatkan kesadaran masyarakat dalam memperbaiki pola PHBS tersebut seperti, memberikan penyuluhan kepada masyarakat tentang arti dan pentingnya hidup bersih dan sehat tersebut, setiap rumah agar memiliki jamban keluarga (JAGA), sarana air bersih (SAB) yang cukup, tempat sampah yang memadai, sarana pembuangan air limbah (SPAL), ventilasi rumah yang standar, kepadatan rumah, lantai rumah dan lain-lain.

Responden yang tidak pernah mengikuti penyuluhan cenderung memiliki perilaku hidup yang kurang bersih dan sehat sebanyak 71 orang $(78 \%)$, lebih besar dibandingkan dengan jumlah responden yang pernah mengikuti penyuluhan yaitu, 45 orang (53,6\%). Dari hasil uji statistik Chi-Square diperoleh nilai $p$ $=0,001$ lebih kecil dari $\alpha=0,05$, yang artinya Ho ditolak (Ha diterima). Jadi dapat disimpulkan bahwa terdapat hubungan yang bermakna antara penyuluhan dengan PHBS pada tatanan rumah tangga di Desa Mendalok, Wilayah kerja Puskesmas Semudun, Kecamatan Sungai Kunyit.

Penelitian ini sejalan dengan penelitian yang dilakukan oleh Sutomo (2018), yang mengatakan bahwa terdapat hubungan yang bermakna antara penyuluhan sebelum dan sesudah dengan PHBS dengan jumlah sampel 120 di wilayah Sidoarjo. Hasil penelitian ini juga sejalan dengan pendapat yang dikemukakan oleh Claar Et Al, (2018) yang mengartikan penyuluhan sebagai jenis pendidikan pemecahan masalah yang berorientasi kepada tindakan yang mengajarkan sesuatu, mendemonstrasikan, memotivasi, tapi tidak melakukan pengaturan dan juga tidak melaksanakan program yang bersifat nonedukatif. Penyuluhan dapat dipahami sebagai lima proses yakni, sebagai proses penyebaran informasi, proses penerangan, proses perubahan perilaku, proses pendidikan, dan proses rekayasa sosial. 
Hasil penelitian ini tidak sejalan dengan penelitian yang dilakukan oleh Wati \& Ridlo (2020) yang menyatakan tidak adanya hubungan antara penyuluhan dengan perilaku hidup bersih dan sehat pada masyarakat di Kelurahan Rangkah Kota Surabaya ( $p$ value $=0,850)$.

Penelitian ini menemukan bahwa masyarakat yang tidak pernah mengikuti penyuluhan cenderung berperilaku hidup kurang bersih dan sehat, $78,0 \%$, lebih besar dibandingkan dengan yang pernah mengikuti penyuluhan. Penyebabnya berkenaan dengan minimnya informasi tentang PHBS dari petugas penyuluhan. Oleh karena itu, harus dicarikan solusinya oleh instansi terkait terutama pihak Puskesmas Semudun Kecamatan Sungai Kunyit. Pemecahan masalah ini dapat berupa langkah-langkah seperti mensosialisasikan PHBS melalui baliho, memasang pamflet informasi pada papan pengumuman dan lain sebagainya.

Peran anggota rumah tangga dalam menerapkan PHBS di Desa Mendalok, Kecamatan Sungai Kunyit dalam kehidupan sehari-hari dapat dilakukan dengan cara mengajak anggota rumah tangga lain untuk berPHBS melalui kelompok dasawisma dengan cara berpartipasi dalam kegiatan di masyarakat terkait PHBS seperti Posyandu dan gerakan pemberantasan sarang nyamuk, menjadi kader pemberdayaan anggota rumah tangga, dan menjalin kerjasama dengan tim di tingkat kampung untuk memberikan penyuluhan perorangan, kelompok, dan penyuluhan massa.

Diketahui bahwa dari 38 responden yang berpendidikan dasar cenderung memiliki perilaku hidup kurang bersih dan sehat sebesar 22 orang (57,9\%). Selanjutnya, dari 114 responden yang berpendidikan menengah, terdapat 83 orang $(72,8 \%)$ yang juga cenderung memiliki perilaku hidup kurang bersih dan sehat. 11 orang $(47,8 \%)$ dari 23 responden yang berpendidikan tinggi cenderung memiliki perilaku hidup kurang bersih dan sehat. Hasil uji statistik Chi-Square diperoleh nilai $p$ $=0,032$ lebih kecil dari $\alpha=0,05$ yang artinya Ho ditolak (Ha diterima), jadi dapat disimpulkan bahwa terdapat hubungan yang bermakna antara tingkat pendidikan kepala keluarga dengan PHBS pada tatanan rumah tangga di Desa Mendalok wilayah Kerja Puskesmas Semudun, Kecamatan Sungai Kunyit.

Hasil penelitian yang diperoleh di lapangan menginformasikan bahwa kecenderungan masyarakat yang memiliki pendidikan menengah dan dasar beresiko memiliki perilaku hidup kurang bersih dan sehat sebesar 72,8\% (83 orang) dan 57,9\% (22 orang) dibandingkan dengan masyarakat yang memiliki pendidikan tinggi. Kondisi ini menunjukkan bahwa semakin rendah pendidikan masyarakat, semakin berkurang pengetahuan masyarakat tentang.

Hasil penelitian ini sejalan dengan penelitian yang dilakukan oleh Sutomo (2018), yang mengatakan bahwa terdapat hubungan yang bermakna antara pendidikan dengan PHBS dengan jumlah sampel 95 orang di wilayah kerja Puskesmas Kampung Bali Kota Pontianak. Hasil penelitian ini juga sejalan dengan pendapat yang dikemukakan oleh Notoatmodjo (2018), pendidikan adalah segala upaya yang direncanakan untuk mempengaruhi orang lain baik individu, kelompok atau masyarakat sehingga mereka melakukan apa yang diharapkan. Pada umumnya semakin tinggi pendidikan seseorang, 
semakin baik pula tingkat pengetahuannya. Makin tinggi tingkat pengetahuan seseorang, makin mudah menerima informasi sehingga semakin banyak pula pengetahuan yang dimiliki.

$$
\text { Pendidikan dapat }
$$

meningkatkan kematangan intelektual seseorang. Kematangan intelektual ini berpengaruh pada wawasan, cara berfikir untuk pengambilan keputusan maupun dalam pembuatan kebijakan. Semakin tinggi pendidikan formal, akan semakin baik pengetahuan tentang kesehatan.

Hasil penelitian ini tidak sejalan dengan penelitian yang dilakukan oleh Imanda (2018), yang menyatakan bahwa tidak ada hubungan antara pendidikan PHBS pada pedagang hidangan istimewa kampung (HIK) di Kecamatan Pasar Kliwon dan Jebres, Kotamadya Surakarta ( $p$ value $=0,256)$.

Rendahnya pendidikan masyarakat berpengaruh terhadap pengetahuan, sikap dan perilaku mereka untuk tidak melakukan pola PHBS. Oleh karena itu, hal ini tentunya akan berdampak bagi masyarakat yang berada di wilayah kerja Puskesmas Semudun, Kecamatan Sungai Kunyit dengan persentase $65,1 \%$ dan $21,7 \%$ yang beresiko memiliki perilaku hidup bersih dan sehat kurang. Dengan demikian, perlu adanya upaya-upaya yang dapat dilakukan untuk meningkatkan pengetahuan masyarakat dengan memberikan penyuluhan untuk mencegah meningkatnya pola PHBS karena pendidikan kesehatan dapat diperoleh dari berbagai sumber antara lain dari penyuluhan kesehatan yang dilakukan oleh pemerintah, dari media massa maupun elektronik dan dari pendidikan formal.

\section{KESIMPULAN}

Hasil penelitian tentang perilaku hidup bersih dan sehat (PHBS) di Desa Mendalok wilayah kerja Puskesmas Semudun, Kecamatan Sungai Kunyit, dapat ditarik beberapa kesimpulan sebagai berikut:

1. terdapat hubungan antara tingkat pengetahuan kepala keluarga dengan PHBS pada tatanan rumah tangga $(p=0,006)$.

2. Ada hubungan antara sikap kepala keluarga dengan PHBS pada tatanan rumah tangga $(p=0,022)$.

3. Ada hubungan antara penyuluhan dengan PHBS yang pernah di ikuti oleh KK pada tatanan rumah tangga $(p=0,001)$.

4. Ada hubungan antara tingkat pendidikan kepala keluarga dengan PHBS pada tatanan rumah tangga $(p=0,032)$.

\section{REKOMENDASI}

Diharapkan

Puskesmas

Semudun, Kabupaten Mempawah meningkatkan lagi penyuluhan kesehatan, minimal 1 bulan sekali khususnya tentang PHBS di Desa Mendalok. Penyuluhan tersebut dapat disampaikan melalui aktifitas bersama masyarakat dengan kegiatan gotong royong dan bersama-sama saling memberikan contoh yang nyata guna meningkatkan perilaku hidup bersih dan sehat, dan mengadakan lomba kebersihan lingkungan. $\mathrm{Hal}$ ini ditujukan untuk menarik respon masyarakat agar memperhatikan dan membersihkan lingkungan sekitar yang bertujuan untuk meningkatkan pola PHBS di Desa Mendalok wilayah kerja Puskesmas Semudun Kecamatan Sungai Kunyit. 
UCAPAN TERIMA KASIH

Terimakasih diucapkan kepada masyarakat di wilayah kerja Puskesmas Semudun, Kabupaten Mempawah yang telah berkontribusi secara langsung dalam pengambilan data, petugas sanitarian yang telah membantu dalam menentukan lokasi dan tempat dalam penelitian ini serta Fakultas IImu Kesehatan Universitas Muhammadiyah Pontianak yang telah mewadahi penelitian ini.

\section{DAFTAR PUSTAKA}

Arikunto, S. (2016). Prosedur Penelitian Suatu Pendekatan Praktik (Vol. 3). Jakarta: Rineka Cipta.

Azwar Azrul. (2017). Metodologi Penelitian Kedokteran dan Kesehatan Masyarakat. Batam: Binapura.

Claar Et Al. (2018). Determinants of health-promoting lifestyle behaviour in the rural areas of Hungary (Vol. 25). New York: Health Promotion International.

Imanda Amalia. (2018). Hubungan Antara Pendidikan, Pendapatan dan Perilaku Hidup Bersih dan Sehat (PHBS) pada Pedagang Hidangan Istimewa Kampung (HIK) di Pasar Kliwon dan Jebres Kota Surakarta. Kesehatan Masyarakat, 47(33), 1-90.

Kementerian Kesehatan RI. (2020). Pedoman Pembinaan Perilaku Hidup Bersih dan Sehat (PHBS). In Peraturan Menteri Kesehatan Republik Indonesia Nomor: 2269/Menkes/Per/XI/2011 (pp. 1-97). Jakarta.

Kesehatan, K., \& RI. (2017). Buku Pedoman pembinaan Perilaku Hidup Bersih dan Sehat di
Tatanan Rumah Tangga. Jakarta: kementerian kesehatan RI.

Notoatmodjo, S. (2018). Kesehatan Masyaratak Ilmu dan Seni. In IImu dan Seni. Rineka Cipta. Jakarta.

Sugiyono. (2018). Metode Penelitian Administrasi. Bandung: Alfa Beta.

Sutomo. (2018). Hubungan Antara Pengetahuan, Sikap dan Perilaku Hidup Sehat Kepala Keluarga dengan Kejadian ISPA di Wialayah Kerja Puskesmas Jatiroto Kabupaten Wonogiri. Jurnal Kesehatan Lingkungan, 1(2), 12-14.

Wati, P. D. C. A., \& Ridlo, I. A. (2020). Hygienic and Healthy Lifestyle in the Urban Village of Rangkah Surabaya. Jurnal PROMKES, 8(1), 47. https://doi.org/10.20473/jpk.v8.i1. 2020.47-58 